\title{
Synthesis and Hydrophilic Performance of Poly(Lactic Acid)-Poly(Ethylene Glycol) Block Copolymers
}

\author{
Gang Xu1,2, Sihao Chen ${ }^{1,2}{ }^{*}$, Xiao Yan ${ }^{2,3}$, Chunyu Yang1,2, Zhichang Chen ${ }^{1,2}$ \\ ${ }^{1}$ College of Chemistry and Chemical Engineering, Shanghai University of Engineering Science, Shanghai, China \\ ${ }^{2}$ Multidisciplinary Center for Advanced Materials, Shanghai University of Engineering Science, Shanghai, China \\ ${ }^{3}$ College of School of Automotive Engineering, Shanghai University of Engineering Science, Shanghai, China \\ Email: "haosihaosi@163.com
}

Received 16 January 2016; accepted 20 March 2016; published 24 March 2016

Copyright (C) 2016 by authors and Scientific Research Publishing Inc.

This work is licensed under the Creative Commons Attribution International License (CC BY).

http://creativecommons.org/licenses/by/4.0/

C) (i) Open Access

\begin{abstract}
Lactide was synthesized using lactic acid and stannous octoate as raw material and catalyst, respectively. Poly(lactic acid)-poly(ethylene glycol) (PLA-PEG) was prepared by lactide and poly (ethylene glycol) (PEG) via ring-opening polymerization. The most appropriate technological conditions of synthesis of lactide were researched in the paper. The copolymers were measured by Infrared spectroscopy (IR) and ${ }^{1} \mathrm{H}$ nuclear magnetic resonance (1H NMR). The results proved that the lactide and PLA-PEG were synthesized successfully. Hydrophilic performance of the copolymer was measured by a water contact angle tester after prepared into a flat membrane. The water contact angle changed from $81.5^{\circ}$ to $71.6^{\circ}$, which proved that the hydrophily of PLA-PEG was better than PLA.
\end{abstract}

\section{Keywords}

Lactide, Poly(Lactic Acid)-Poly(Ethylene Glycol) (PLA-PEG), Prepare, Hydrophily

\section{Introduction}

Polylactic acid (PLA) is one of environment-friendly biodegradable polymers which can be synthesized [1] by ring opening polymerization (ROP) of lactide. A typical process is using catalysts such as tin, zinc, aluminum and lead, initiators such as n-, sec- and tert-butyl lithium, and solvents such as diphenyl ether, toluene and chloroform. However, many of these components are toxic; thereby this process is required to remove the impurities

\footnotetext{
${ }^{*}$ Corresponding author.
}

How to cite this paper: Xu, G., Chen, S.H., Yan, X., Yang, C.Y. and Chen, Z.C. (2016) Synthesis and Hydrophilic Performance of Poly(Lactic Acid)-Poly(Ethylene Glycol) Block Copolymers. American Journal of Analytical Chemistry, 7, 299-305. 
from the product [2]. PLA has good mechanical properties, thermal plasticity and biocompatibility, which has been approved by the US Food and Drug Administration for application in tissue engineering, medical materials, and drug carriers. PLA has great application in biomedical field as it doesn't produce toxic or carcinogenic effects in local tissues [3]. It also has good biodegradability, biocompatibility, non-immunogenicity and miscibility with other polymers [4]. However, PLA applications are limited by its hydrophilicity, long degradation time [5] and low drug loading of polar drug. So poly(lactic acid) has been aggregated with other biomaterials to improve its disadvantages [6]-[8]. On the other hand, PEG has a lot of advantages, which is different from PLA, such as great hydrophilicity, flexibility, resistance to immunological recognition and good biocompatibility [9] [10]. Therefore, PEG could be used to improve the performance of PLA.

The synthesis of lactide and PLA-PEG block copolymer [11]-[14] will be studied in this paper. In particular, the technological conditions of synthesis of lactide have been discussed. ${ }^{1} \mathrm{H}$ nuclear magnetic resonance (NMR) and infrared spectroscopy (IR) were employed to characterize the chemical structures of lactide and PLA-PEG block copolymer. And the hydrophilic performance of films was measured by a water contact angle tester.

\section{Materials and Methods}

\subsection{Materials}

Lactide acid (98\%), poly(ethylene glycol) (PLA) $(\mathrm{Mw}=600)$ and poly(ethylene glycol) (PLA) (Mw = 1000) were purchased from Tansoole (China). dichloromethane, diethyl ether and acetone which are analytically pure (AR) were purchased from Sinopharm Chemical Reagent Co., Ltd. (China). Tin(II) bis(2-ethylhexanoate) (stannous octoate) were obtained from Sigma, St Louis, MO, USA. Stannous octoate was dried and purified using anhydrous magnesium sulfate, dry toluene and vacuum distillation.

\subsection{Synthesis of Lactide}

Lactic acid and catalyst (stannous octoate) were added into a three-necked round-bottomed flask with a magnetic stirring and a thermometer. Mixture was allowed to react at $110^{\circ} \mathrm{C}$ for $1 \mathrm{~h}$, until no more water was steamed out. After that, the measure was allowed to react at $200^{\circ} \mathrm{C}$ for $8 \mathrm{~h}$ with vacuum pump working. The product was collected by a flask, and dried at room temperature. Before using, the product was refined three times.

\subsection{Synthesis of PLA-PEG Block Copolymer}

PLA-PEG block copolymer was prepared using ring opening polymerization of lactide. The prepared block copolymers are abbreviated as PLA-PEG (Scheme 1). Briefly, lactide and PEG were dried in vacuum drying oven at $50^{\circ} \mathrm{C}$ overnight, respectively. PEG and L-lactide was introduced into a three-necked flask equipped with a magnetic stirring bar. After $10 \mathrm{~min}$, stannous octoate was introduced into the flask using as initiator. The flask was sealed and the measure was allowed to react at $200^{\circ} \mathrm{C}$ for $8 \mathrm{~h}$ under $\mathrm{N}_{2}$. The obtained product was dissolved in dichloromethane, and precipitated by acetone, then dried at $40^{\circ} \mathrm{C}$ in a vacuum oven overnight. The product was washed with anhydrous ethyl ether for three times before dried again.

\subsection{Purification of Lactide and PLA-PEG Block Copolymer}

The rough lactide was recrystallized by ethyl acetate for three times [15]. Then, the refine lactide was dried in vacumm at $40^{\circ} \mathrm{C}$ for $10 \mathrm{~h}$.

The copolymer was dissolved in dichloromethane with stirring at room temperature. After insolubles were removed, diethyl ether was added into the solution as sedimentation agent. The precipitated products were sepa-

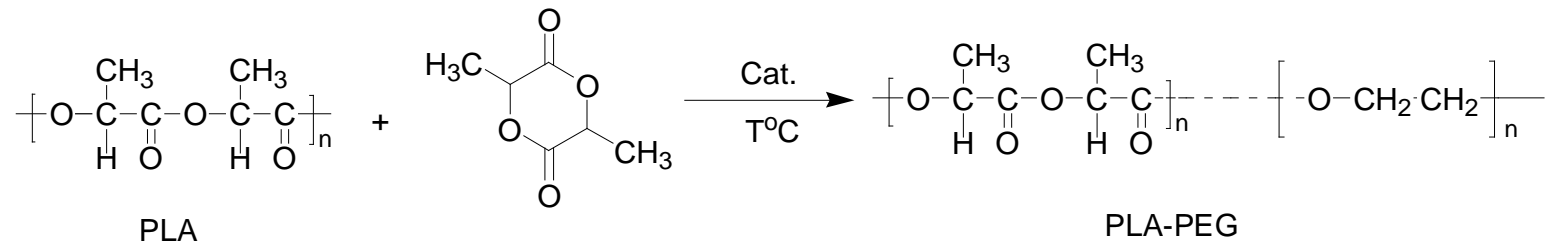


rated by centrifugation, washed by ethanol and dried in vacumm at $50^{\circ} \mathrm{C}$ for $10 \mathrm{~h}$.

\subsection{Characterization}

The chemical structures of lactide and PLA-PEG block copolymer were confirmed by nuclear magnetic resonance (NMR) and infrared spectroscopy (IR). ${ }^{1} \mathrm{H}$ NMR spectra were recorded on Varian Unityinova 500 NMR Spectrometer operated at $500 \mathrm{MHz}$ at $60^{\circ} \mathrm{C}$, and d8-toluene was used as solvent. Infrared spectroscopy (IR) was performed using a Nicolet FT-IR spectrometer in a wavenumber range from 500 to $4000 \mathrm{~cm}^{-1}$ with a resolution of $2 \mathrm{~cm}^{-1}$. The dried sample were mixed with $\mathrm{KBr}$ crystals and pressed into pellets before measurements.

The hydrophilic performance of films was measured by a water contact angle tester. The samples were cut into $20 \mathrm{~mm} \times 20 \mathrm{~mm}$ and attached to several clean glass slides in order to make sure the contact surface flat. Then, one droplet of distilled water was dropped onto the random area of each film at room temperature and humidity. Each sample needs to be measured five times.

\section{Results and Discussion}

\subsection{The Technological Conditions of Synthesis of Lactide}

High products rate can be achieved under appropriate conditions temperature and pressure. Different temperatures and pressures conditions of reaction were discussed. Table 1 shows the detail data in preparation.

Figure 1 shows that the dehydrating amount of reaction increases at $110^{\circ} \mathrm{C}-150^{\circ} \mathrm{C}$ and decreases after $150^{\circ} \mathrm{C}$. The maximum dehydration rate is $78.9 \%$. Table 1 shows that the best pressure boost method is to keep reaction at ambient pressure and change to reduced pressure after a period of time. As we are interested in the influence of pressure value on the dehydration rate, different pressure values are listed on Table 2. It shows that with the increasing of pressure, more water can be distilled. However, the Figure 1 shows the most suitable reaction temperature is $150^{\circ} \mathrm{C}$. As if temperature is too low, lactic acid would not react, and if temperature too high, most of the reactant would be steamed out, which both lead to a poor yield. According to the results, a flexible pressure control process and an appropriate highest reaction temperature can make the best use of raw materials and obtain a great production.

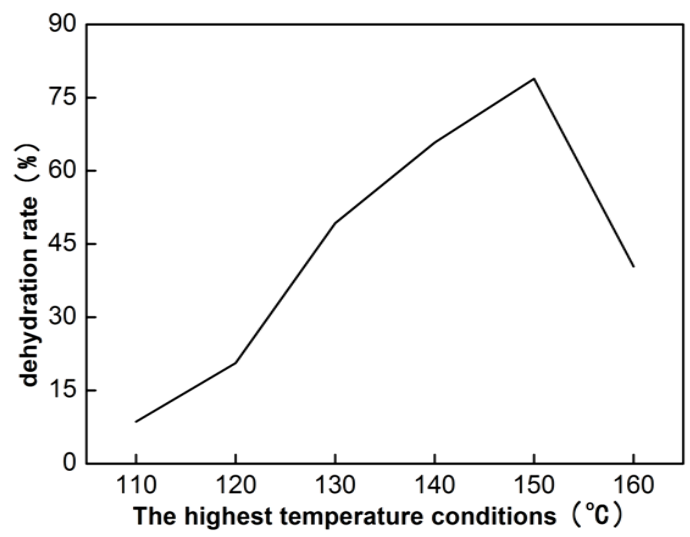

Figure 1. The influence of reaction temperature on the dehydration rate.

Table 1. Pressure condition of synthesis of lactide.

\begin{tabular}{|c|c|c|c|c|c|}
\hline Pressure condition & $\begin{array}{c}\text { Highest } \\
\text { temperature/ }{ }^{\circ} \mathrm{C}\end{array}$ & $\begin{array}{c}\text { Dosage } \\
\text { of catalyst }\end{array}$ & $\begin{array}{l}\text { Reaction } \\
\text { time/h }\end{array}$ & $\begin{array}{l}\text { Dehydration } \\
\text { rate/\% }\end{array}$ & $\begin{array}{l}\text { Emulsion } \\
\text { in condenser pipes }\end{array}$ \\
\hline Normal pressure & 150 & $1 \%$ & 12 & $45.8 \%$ & Yellow emulsion \\
\hline $\begin{array}{l}\text { From normal pressure } \\
\text { to reduced pressure }\end{array}$ & 150 & $1 \%$ & 10 & $74.4 \%$ & $\begin{array}{l}\text { Trace amounts of } \\
\text { yellow emulsion }\end{array}$ \\
\hline Reduced pressure & 150 & $1 \%$ & 8 & $20.4 \%$ & A lot of yellow emulsion \\
\hline
\end{tabular}


Table 2. The influence of pressure value on the dehydration rate.

\begin{tabular}{ccc}
\hline Pressure value/Mpa & Dehydration rate/\% & Emulsion in condenser pipes \\
\hline-0.076 & 74.4 & Trace amounts of yellow emulsion \\
-0.053 & 66.8 & Trace amounts of yellow emulsion \\
-0.037 & 57.1 & Yellow emulsion \\
-0.019 & 52.3 & Yellow emulsion \\
\hline
\end{tabular}

\subsection{The Technological Conditions of Synthesis of PLA-PEG Block Copolymer}

The reaction temperature and time are both important to the properties of PLA-PEG. Therefore, Different reaction temperatures and times were discussed in here. Figure 2 and Figure 3 shows that relationship of different reaction temperature and reaction time with viscosity average molecular weight.

Figure 2 and Figure 3 both show the viscosity average molecular weight of products increase at first and decrease after. Analysis: there are two kinds of reaction in the process of reaction using stannous octylic acid as catalyst: catalytic polymerization and catalytic degradation. In the whole reaction, two reactions exist at the same time, competing with each other. At low temperature, catalytic polymerization reaction rate faster than the degradation rate, and with the increasing of temperature, the delta difference in speed comes bigger, so the molecular weight becomes bigger; moreover, when the temperature comes over $160^{\circ} \mathrm{C}$, the degradation rate faster than polymerization rate, and as temperatures continue to rise back, degradation rate grows, so molecular weight gets smaller. According to molecular weight in the process of reaction time, in the process of response time less than 6 hours, with the increase of time, the degree of polymerization of reactants grows, however, with the reaction time extend, reaction polymerization rate gradually begins to slow and the side reaction comes more, which begins to cause the molecular weight of the product decrease. So in this progress, we take $160^{\circ} \mathrm{C}$ and 6 hours as the best reaction conditions.

\subsection{Characterization of L-Lactide}

Figure 4 and Figure 5 show the ${ }^{1} \mathrm{H}$ NMR spectrum and Infrared spectroscopy spectrum of L-lactide monomer.

Figure 4 is the infrared spectrum of L-lactide. And table1 has been listed peak position of L-lactide. 1770 $\mathrm{cm}^{-1}$ was the stretching vibration peak of $\mathrm{C}=\mathrm{O}, 1095 \mathrm{~cm}^{-1}$ was the stretching vibration peak of $\mathrm{C}-\mathrm{O}$, which proved the existence of ester. The peaks at $1389 \mathrm{~cm}^{-1}$ and $1458 \mathrm{~cm}^{-1}$ were, respectively, attributed to the methyl peak and deformation vibration of C-H. Thus, there were two peaks at $2931 \mathrm{~cm}^{-1}$ and $2996 \mathrm{~cm}^{-1}$ which coming from stretching vibration of C-H. The peak at $935 \mathrm{~cm}^{-1}$ and $652 \mathrm{~cm}^{-1}$ were the framework vibration of lactide' ring structure. Those all can prove the existence of lactic acid chain. Figure 5 is the ${ }^{1} \mathrm{H}$ NMR spectrum of lactide shows the peaks related to the proton at 5.2 and $1.6 \mathrm{ppm}$, respectively. The relative area of proton peaks was according with the lactide monomers. Take all above into conclusion, this polymer was the lactide.

\subsection{Characterization of PLA-PEG Block Copolymers}

Figure 6 and Figure 7 show the ${ }^{1} \mathrm{H}$-NMR spectrum and Infrared spectroscopy spectrum of PLA-PEG block copolymers.

Figure 6 is the $1 \mathrm{H}$-NMR spectrum of PLA-PEG block copolymers. It shows the peaks related to the proton at 5.2, 3.6 and 1.6 ppm, respectively. Through the comparison for Figure 2 and Figure 4, the proton at 3.6 is different, which was the absorbance peak of hydrogen $(\mathrm{H})$ in ethylene glycol chains.

Figure 7 is the infrared spectrum of PLA-PEG block copolymers. The $1758 \mathrm{~cm}^{-1}$ was the stretching vibration peak of $\mathrm{C}=\mathrm{O}, 1095 \mathrm{~cm}^{-1}$ was the stretching vibration peak of $\mathrm{C}-\mathrm{O}$, which proved the existence of ester. 1369 $\mathrm{cm}^{-1}, 1456 \mathrm{~cm}^{-1}$ were, respectively, attributed to methyl and deformation vibration of C-H. $2877 \mathrm{~cm}^{-1}$ was the stretching vibration peak of $-\mathrm{CH}_{2}$, which showed the difference with lactide. In conclusion, PLA-PEG block copolymers were prepared successfully.

\subsection{Surface Hydrophilicity of Polymer Films}

Table 3 shows the water contact angle variations of PLA, PLA-PEG (600) film, and PLA-PEG (1000) film. It 


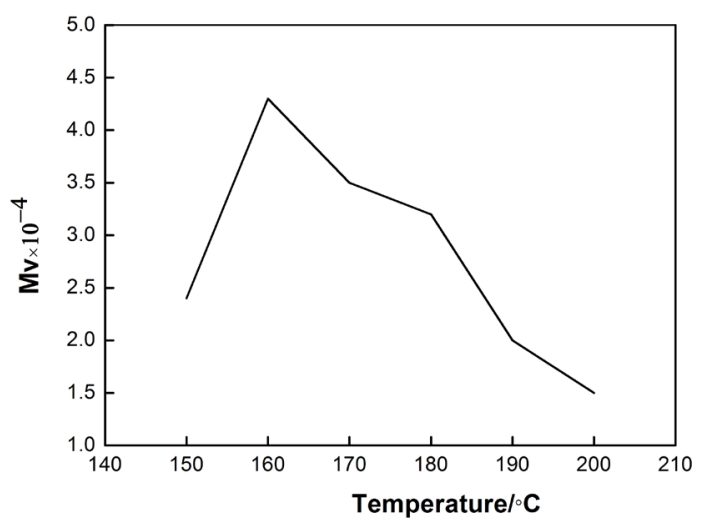

Figure 2. The diagram of reaction temperature and viscosity average molecular weight.

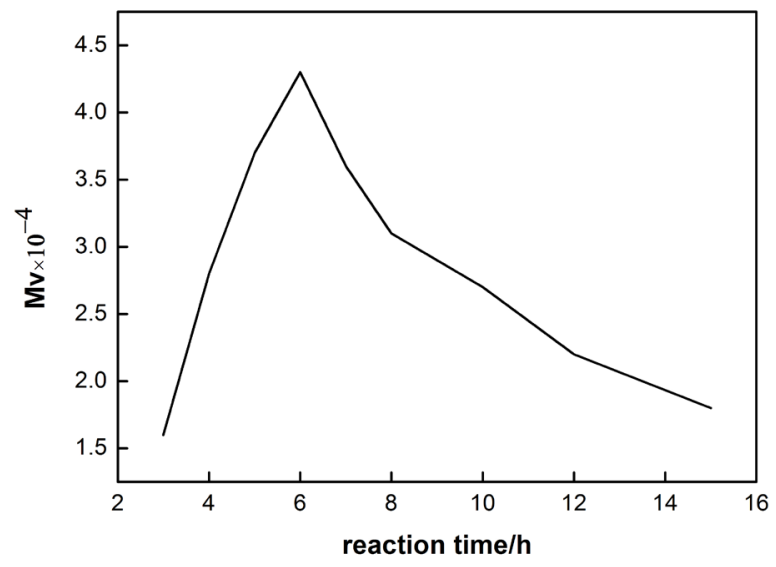

Figure 3 . The diagram of reaction time and viscosity average molecular weight.

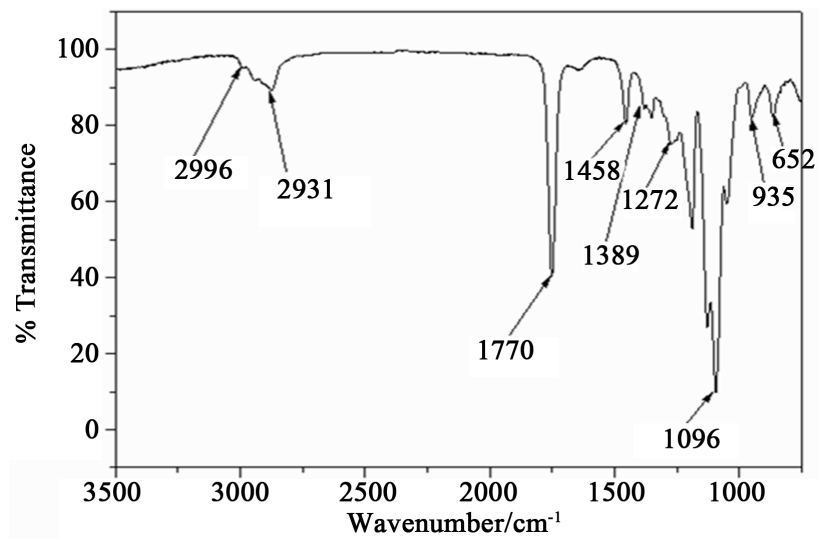

Figure 4. IR spectra of L-lactide.

Table 3. Water contact angle of PLA and PLA-PEG block copolymers.

\begin{tabular}{ccc}
\hline Polymer & $\mathrm{M}_{\eta}$ & Water contact angle $\left(^{\circ}\right)$ \\
\hline PLA & 21754 & 81.5 \\
PLA-PEG (600) & 33428 & 76.2 \\
PLA-PEG (1000) & 40147 & 71.7 \\
\hline
\end{tabular}




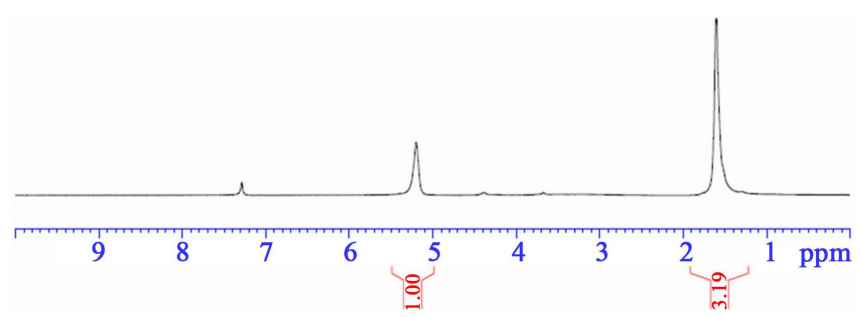

Figure 5. ${ }^{1} \mathrm{H}$ NMR spectrum of L-lactide.

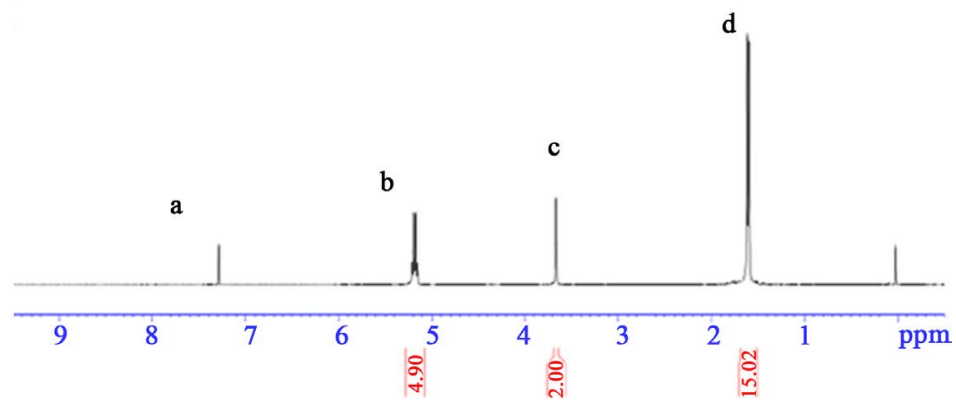

Figure 6. 1H-NMR spectrum of PLA-PEG block copolymers.

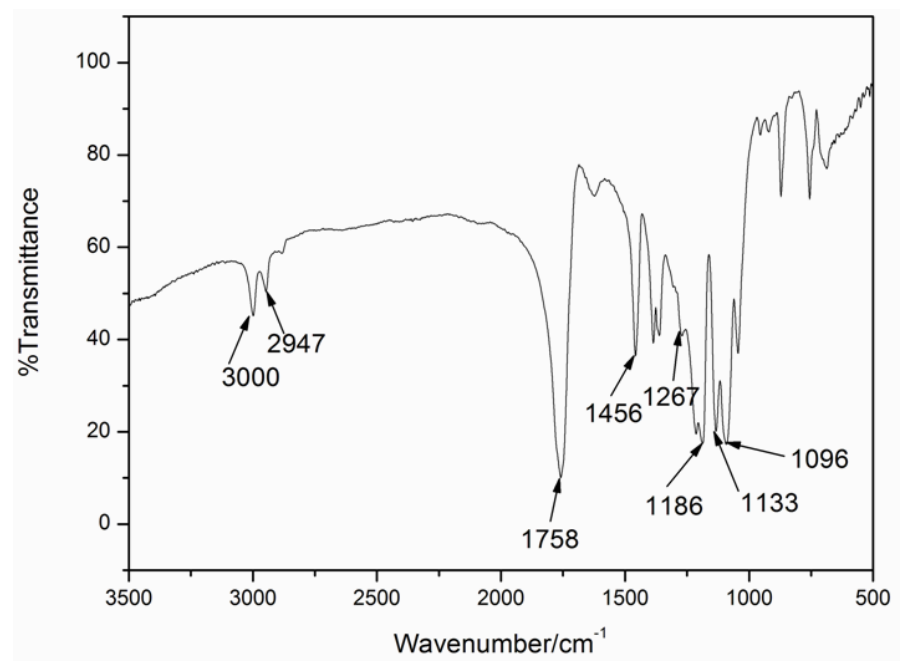

Figure 7. IR spectra of PLA-PEG block copolymers.

can be seen that the average water contact angle of the pure PLA was $81.5^{\circ}$, because the $\mathrm{M}_{\eta}$ was only 21,754 . The average water contact angle of PLA-PEG (1000) block copolymers was $71.7^{\circ}$. Compare with the average water contact angle of PLA-PEG (600) block copolymers, the water contact angle decreased with the increasing weight of molecular. The hydrophilic performance of PLA-PEG copolymers were totally better than PLA, which was attribute to the addition of PEG.

\section{Conclusions}

In this paper, the temperature and pressure conditions were confirmed. In the preparation process of lactide, the optimal scheme was that the highest temperature was $150^{\circ} \mathrm{C}$ and the pressure decreased with temperature increased was requested. Meanwhile, a higher pressure number may contribute to a high dehydration rate.

A series of amphiphilic block polymers were synthesized by ring-opening polymerization of LA and PEG. Lactide, and PLA-PEG block copolymers were characterized by nuclear magnetic resonance (NMR) and infrared spectroscopy (IR), which confirmed that those were synthesized successfully. The water contact angle de- 
creased with increasing weight of the molecular, which was less than PLA's. The hydrophilic performance of PLA-PEG copolymers was totally better than PLA, which attributed to the addition of PEG.

\section{Acknowledgements}

This research work was supported by Shanghai Major Construction Projects (11XK18BXKCZ1205), the Program of Shanghai Science and Technology Capacity Building Project Local Universities (11490501500), and the Foundation of Shanghai University of Engineering Science (E1-0501-15-0105) and the project of Shanghai universities young teacher training scheme (ZZGCD15037).

\section{References}

[1] Ro, A.J., Huanga, S.J. and Weiss, R.A. (2009) Synthesis and Properties of Random Poly(Lactic Acid)-Based Ionomers. Polymer, 50, 1134-1143. http://dx.doi.org/10.1016/j.polymer.2008.12.043

[2] Achmad, F., Yamane, K., Quan, S. and Kokugan, T. (2009) Synthesis of Polylactic Acid by Direct Polycondensation under Vacuum without Catalysts, Solvents and Initiators. Chemical Engineering Journal, 151, 342-350. http://dx.doi.org/10.1016/j.cej.2009.04.014

[3] Tanase, C.E. and Spiridonb, I. (2014) PLA/Chitosan/Keratin Composites for Biomedical Applications. Materials Science and Engineering: C, 40, 242-247. http://dx.doi.org/10.1016/j.msec.2014.03.054

[4] Abdelwahaba, M.A., Flynnb, A. and Chiou, B.-S. (2012) Thermal, Mechanical and Morphological Characterization of Plasticized PLA-PHB Blends. Polymer Degradation and Stability, 97, 1822-1828. http://dx.doi.org/10.1016/j.polymdegradstab.2012.05.036

[5] Weng, Y.-X., Jina, Y.-J., Menga, Q.-Y., et al. (2013) Biodegradation Behavior of Poly(Butylene Adipate-Co-Terephthalate) (PBAT), Poly(Lactic Acid) (PLA), and Their Blend Under Soil Conditions. Polymer Testing, 32, 918-926. http://dx.doi.org/10.1016/j.polymertesting.2013.05.001

[6] Weng, Y.-X., Wang, L., Zhang, M., et al. (2012) Biodegradation Behavior of P(3HB, 4HB)/PLA Blends in Real Soil Environments. Polymer Testing, 32, 60-70. http://dx.doi.org/10.1016/j.polymertesting.2012.09.014

[7] Cavallaroa, G., Craparoa, E.F., Sardo, C., et al. (2015) PHEA-PLA Biocompatible Nanoparticles by Technique of Solvent Evaporation from Multiple Emulsions. International Journal of Pharmaceutics, 495, 719-727. http://dx.doi.org/10.1016/j.ijpharm.2015.09.050

[8] Byuna, Y., Rodriguezb, K. and Han, J.H. (2015) Improved Thermal Stability of Polylactic Acid (PLA) Composite Film via PLA- $\beta$-Cyclodextrin-Inclusion Complex Systems. International Journal of Biological Macromolecules, 81, 591598. http://dx.doi.org/10.1016/j.ijbiomac.2015.08.036

[9] Zhu, A., Lu, P. and Wu, H. (2007) Immobilization of Poly([Var Epsilon]-Caprolactone)-Poly(Ethylene Oxide)- Poly([Var Epsilon]-Caprolactone) Triblock Copolymer on Poly(Lactide-Co-Glycolide) Surface and Dual Biofunctional Effects. Applied Surface Science, 253, 3247-3253. http://dx.doi.org/10.1016/j.apsusc.2006.07.036

[10] Boutena, P.J.M., Zonjeea, M., Bender, J., et al. (2014) The Chemistry of Tissue Adhesive Materials. Progress in Polymer Science, 39, 1375-1405. http://dx.doi.org/10.1016/j.progpolymsci.2014.02.001

[11] Kulinski, Z., Piorkowska, E., Gadzinowska, K., et al. (2006) Plasticization of Poly(L-Lactide) with Poly(Propylene Glycol). Biomacromolecules, 7, 2128-2135. http://dx.doi.org/10.1021/bm060089m

[12] Reddy, M.M., Vivekanandhana, S. and Misra, M. (2013) Biobased Plastics and Bionanocomposites: Current Status and Future Opportunities. Progress in Polymer Science, 38, 1653-1689. http://dx.doi.org/10.1016/j.progpolymsci.2013.05.006

[13] Piorkowska, E., Kulinski, Z., Galeski, A., et al. (2006) Plasticization of Semicrystalline Poly(L-Lactide) with Poly (Propylene Glycol). Polymer, 47, 7178-7188. http://dx.doi.org/10.1016/j.polymer.2006.03.115

[14] Diao, J.P., Wang, H.X., Chang, N.N., et al. (2015) PEG-PLA Nanoparticles Facilitate siRNA Knockdown in Adult Zebrafish Heart. Developmental Biology, 406, 196-202. http://dx.doi.org/10.1016/j.ydbio.2015.08.020

[15] Kulinski, Z. and Piorkowska, E. (2005) Crystallization, Structure and Properties of Plasticized Poly(L-Lactide). Polymer, 46, 10290-10300. http://dx.doi.org/10.1016/j.polymer.2005.07.101 